\title{
Aprendendo via o Papel de Designer e de Stakeholder: Uma Estratégia Pedagógica para Ensino de IHC
}

\author{
Luã Marcelo Muriana \\ Universidade Estadual de Campinas \\ Campinas, Brasil \\ luamarcelo17@gmail.com
}

\author{
Mauro Dalle Lucca Tosi \\ Universidade Estadual de Campinas \\ Campinas, Brasil \\ maurodlt@hotmail.com
}

\author{
Julio Cesar dos Reis \\ Universidade Estadual de Campinas \\ Campinas, Brasil \\ jreis@ic.unicamp.br
}

\section{RESUMO}

O ensino de IHC demanda práticas colaborativas em grupos que experienciam diferentes papéis no processo de design de software interativos. Neste artigo avaliamos o uso de uma estratégia pedagógica no ensino de IHC em que alunos desenvolvem tanto o papel de designers quanto de stakeholders em uma abordagem de aprendizagem baseada em projeto. Os alunos são divididos em grupos em que a princípio escolhem os temas dos projetos para trabalharem como designers. Entretanto, para simular uma experiência mais próxima do mundo real, em que a escolha de temas de projetos não é possível, os grupos são parificados e têm seus temas trocados. Assim, cada grupo é designer de um projeto com tema não familiar (não definido pelos mesmos) e desenvolve papel de "cliente" do tema por ele escolhido. Para avaliar a percepção de aprendizagem dos alunos em relação à estratégia de ensino elaborada, realizamos um questionário aplicado à turmas de Ciência da Computação e Engenharia da Computação. Com base em 123 respostas analisadas, $96 \%$ dos alunos afirmaram que o projeto os auxiliou positivamente no aprendizado de IHC.

\section{PALAVRAS-CHAVE}

Ensino Baseado em Projeto, Papel de Designer, Ensino de IHC, Design Centrado no Usuário

\section{INTRODUÇÃO}

O ensino de Interação Humano-Computador (IHC) é desafiador devido a interdisciplinaridade demandando o estudo de

Permission to reproduce or distribute, in whole or in part, material extracted from this work, verbatim, adapted or remixed, as well as the creation or production from the content of such work, is granted without fee for non-commercial use, provided that the original work is properly credited.

IHC 2019 Workshop sobre Educação em IHC (WEIHC), Outubro 21-25, 2019, Vitória, Brasil. In Anais Estendidos do XVIII Simpósio Brasileiro sobre Fatores Humanos em Sistemas Computacionais. Porto Alegre: SBC. ( 2019 by the author(s), in accordance with the terms of the Creative Com-mons Attribution-NonCommercial 4.0 International Public License (CC BY-NC 4.0). diferentes conceitos advindos de múltiplas áreas como psicologia, antropologia, etc. Nesse contexto, o ensino de IHC enfrenta diversas barreiras para dirimir as dificuldades dos alunos entenderem as funções na prática tanto de designers quanto de stakeholders (no sentido de clientes interessados no produto) no design da interação de um software. Disciplinas conduzidas em termos puramente teóricos não favorecem os alunos tomarem consciência das tarefas envolvidas em diversas fases de um projeto da interação. Similarmente, quando os alunos não simulam o papel de stakeholders pouco se sensibilizam em como elucidar as necessidades dos usuários e a compreender a importância do design centrado em usuários [5], técnicas participativas [6] e avaliação das interfaces propostas.

A literatura de ensino de IHC pouco tem estudado meios de se promover e averiguar o aprendizado de diferentes papéis no processo de design de software [1] no contexto de disciplinas na graduação no ensino superior. Em cursos como Ciência da Computação e Engenharia da Computação, que enfatizam principalmente na suas grades disciplinas com conceitos técnicos e matemáticos, a disciplina de IHC desenvolve um papel chave em colaborar na ampliação da visão e entendimento pelos alunos dos efeitos dos sistemas de software construídos. Nesse aspecto, a abordagem de Aprendizado Baseado em Projeto (ABP) pode colaborar no processo de ensino-aprendizagem, permitindo que os alunos entendam os desafios e problemas inerentes das fases de desenvolvimento de uma solução de design.

Para Bender (2015) [2], "a aprendizagem baseada em projetos é um modelo de ensino que consiste em permitir que os alunos confrontem as questões e os problemas do mundo real que consideram significativos, determinando como abordá-los e, então, agindo de forma cooperativa em busca de soluções". Ribeiroa (2008) [3] enfatiza que a partir da interação social e a exposição a situações da vida real, os alunos podem ter um aprendizado aprimorado, por permitir que questões como "O que devo fazer?" e "Como farei?" sejam indagadas por eles.

Nesse tipo de abordagem de ensino-aprendizado, os problemas são um estímulo para a aprendizagem. Para Delisle e Oliveira (2000) [4], a ABP é "uma técnica de ensino que 
educa apresentando aos alunos uma situação que leva a um problema que tem de ser resolvido". Embora a ABP aumente a motivação dos alunos para aprender por se tratar de projetos autênticos, realistas e altamente motivadores e envolvente [2], é preciso que os alunos experienciem o fato de que nem sempre eles irão trabalhar com projetos em contexto que são familiarizados e/ou se sintam confortáveis e motivados.

Desta forma, é relevante que os alunos adquiram uma experiência em desenvolver um projeto para um "cliente simulado" em um problema de design (tema) não inicialmente definido pelos mesmos. Assim, desenvolver um processo de ensino aprendizagem dirigido por projeto, no aprendizado de design centrado no usuário considerando técnicas participativas no desenho das interfaces de usuário, pode contribuir para uma melhor apropriação e entendimento da relevância da disciplina de IHC na construção de software como um todo.

Neste artigo, conduzimos um estudo com turmas de Ciência da Computação e Engenharia da Computação visando entender a percepção do aprendizado dos alunos em desenvolverem o papel de designers e stakeholders em uma dinâmica entre grupos que conduziram um projeto completo de construção de interfaces desenvolvido ao longo de um semestre. $\mathrm{Na}$ dinâmica, os alunos formaram grupos e definiram um problema de design a ser desenvolvido durante o semestre todo. Depois dessa fase, o docente sinalizou que um grupo seria stakeholder do outro. Um grupo A que definiu um problema de design $\mathrm{X}$ atua como designer para um grupo $\mathrm{B}$ que definiu um problema de design Y. Nesse sentido, o grupo A atua como stakeholder para o grupo B e vice-versa. Logo, o grupo $\mathrm{B}$ atua como designer tratando o problema de design $\mathrm{X}$ definido inicialmente pelo grupo A.

Esta investigação foi conduzida ao longo de dois semestres completos (um semestre para cada turma). O projeto dos grupos foi organizado em diferentes fases (definidas a priori pelo docente), nas quais atividades específicas eram esperadas em cada fase, incluindo a clarificação do problema de design, ideação das interfaces, construção de protótipos de alta fidelidade e avaliação das interfaces.

Ao final de cada semestre, os alunos foram convidados a responderem um questionário cujo objetivo foi avaliar a percepção dos mesmos em relação a metodologia adotada. Os dados obtidos evidenciam a eficácia da metodologia em auxiliar no aprendizado mais efetivo dos alunos. Embora eles tenham se sentido desconfortáveis com a troca de papéis, os discentes reconheceram que o desconforto gerado faz parte do cotidiano de profissionais da área e, portanto, foi uma experiência válida.

O restante deste artigo está organizado da seguinte maneira. A próxima seção apresenta a metodologia desta pesquisa, a dinâmica do curso no qual ela foi adotada, o perfil dos participantes, assim como o método utilizado para a coleta de dados e os procedimentos para analisa-los. Em seguida, os resultados observados são apresentados e discutidos. Por fim, descrevemos a conclusão obtida e indicamos trabalhos futuros.

\section{METODOLOGIA Dinâmica do curso}

A disciplina foi organizada em aulas teóricas e práticas. Sendo que, as aulas teóricas foram ministradas em sala de aula e tiveram como objetivo ensinar os fundamentos de IHC aos alunos. As aulas práticas foram realizadas em laboratórios, nos quais os alunos tiveram que utilizar o conhecimento teórico adquirido para solucionar problemas de design.

A disciplina propôs que conceitos ensinados fossem aplicados por meio da execução de um projeto prático para aprimorar o aprendizado dos alunos. O projeto foi desenvolvido por grupos de 4 a 5 pessoas e visou transmitir experiencias próximas das encontradas no cotidiano de um profissional da área, através da aplicação transversal dos conceitos e técnicas de IHC estudados ao longo do semestre.

Os discentes, de maneira autônoma, se dividiram em grupos e escolheram um problema de design para desenvolverem uma solução ao longo do período letivo. Visando simular uma experiência mais próxima da vida real, em que a escolha de temas de projetos nem sempre é possível, os grupos foram parificados e tiveram seus temas invertidos. Dessa forma, ao invés de desenvolverem seus projetos com base no tema escolhido, cada grupo exerceu o papel de designer sobre o tema escolhido por outro grupo. Cada grupo exerceu igualmente papel de stakeholder, no tema primariamente escolhido por eles. Entretanto, duas informações relevantes foram omitidas dos estudantes como parte da dinâmica de ensino. A primeira é que, cada grupo seria vinculado a um grupo par, de forma que um exerceria o papel de stakeholder do outro; a segunda informação é que, ao invés de exercer o papel de designer no assunto definido pelo grupo, os integrantes de cada grupo desenvolveram o papel de designer do tema escolhido pelo seu grupo par. Dessa forma, os alunos trabalharam como stakeholders dos temas por eles desejados e como designers de assuntos, para eles, aleatórios.

Os projetos práticos desenvolvidos pelos grupos consideraram à concepção, modelagem e prototipação de soluções em interfaces de usuário, utilizando os artefatos metodológicos e técnicas ensinadas ao longo do curso. Estes são avaliados no decorrer do semestre através de entregáveis parciais, os quais são consolidados em um relatório final no término do desenvolvimento do projeto.

\section{Participantes}

A estratégia proposta foi aplicada à alunos do quarto/quinto semestre dos cursos de Ciência da Computação $\left(2^{\circ}\right.$ semestre 
de 2018 - 76 alunos matriculados) e de Engenharia da Computação ( $1^{\circ}$ semestre de 2019 - 64 alunos matriculados) durante a disciplina "Construção de Interfaces Homem-Computador". Os participantes não haviam cursado a disciplina anteriormente e não foram previamente informados a respeito da aplicação da metodologia aqui estudada, o que influenciaria na estratégia desenvolvida e, consequentemente, nos resultados obtidos. Ademais, não houve indícios de informações a respeito do método utilizado terem sido transmitidas entre estudantes das diferentes turmas de um semestre para outro.

\section{Coleta de dados e procedimento de análise}

Aplicamos um questionário anônimo no final de cada período letivo para avaliar a metodologia proposta e a percepção dos alunos referente a disciplina ministrada. Para isso, foi utilizada a ferramenta Google Forms ${ }^{1}$, através da qual foram obtidas no total 123 respostas dos alunos participantes em ambos semestres. Além disso, relatos presentes nos relatórios finais de cada grupo também foram considerados.

O questionário foi organizado em cinco seções, responsáveis por obter dados que refletissem a opinião dos estudantes em relação à disciplina como um todo, às aulas práticas, ao projeto, ao professor, e à dedicação do próprio aluno durante o curso. Sendo que, a seção referente ao projeto prático (foco deste estudo) conteve 25 questões, sendo, 3 alternativas, 8 dissertativas e 14 considerando uma escala Likert.

Para a análise dos dados foram considerados os três tipos de questões levantadas aos alunos sobre o projeto. As questões alternativas foram utilizadas para avaliar se os objetivos do projeto foram alcançados na percepção dos estudantes. As dissertativas foram responsáveis por extrair sugestões e comentários a serem considerados em análises qualitativas. Por fim, as perguntas em escala Likert permitiram avaliar quantitativamente a impressão dos discentes sobre o projeto. Adicionalmente, relatos dos alunos no relatório final dos projetos foram considerados e analisados como resultado qualitativo nesta pesquisa.

\section{RESULTADOS E DISCUSSÃO}

A troca de papéis foi inesperado segundo resultado de 123 alunos respondentes. Além de não saberem que, além de serem designers, também atuariam como stakeholders, eles foram surpreendidos com a troca de projetos e com o fato que se tornariam stakeholders do problema de design que eles propuseram. Isso gerou diversas reações nos alunos. Por isso, foi perguntando a eles o quão desconfortáveis eles se sentiram por esse fato e quão desconfortáveis eles se sentiram por se tornarem designers de um projeto que tinha uma problemática que não foi proposta por eles. Resultados presentes na Figura 1 sinalizam que os alunos não se sentiram, de modo

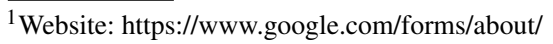

geral, desconfortáveis com a troca de papéis, uma vez que as respostas foram equilibradas.

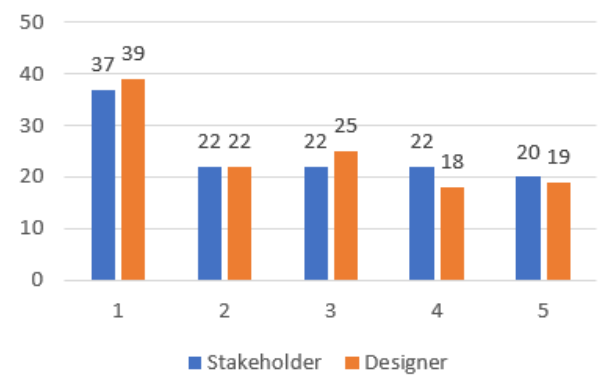

Figura 1: Nível de desconforto dos alunos devido a troca de papéis.

Assim como o nível de desconforto, a motivação dos alunos foi equilibrada, de modo geral, para a troca de papéis, embora tenham havido algumas pequenas discrepâncias. Foi perguntando a eles quão motivados eles se sentiram por se tornarem stakeholders de um problema que eles acreditavam que iriam propor uma solução e o quão motivado se sentirem por atuarem como designers em outro projeto. Os resultados apresentados na Figura 2 demostram que mais alunos se sentiram menos motivados com a troca de papéis: os alunos que marcaram as opções 1 e 2 são maiores do que os que responderam 4 e 5. Isso, talvez, tenha ocorrido por que os alunos ao escolherem um problema de design desejam solucioná-lo por já terem certo entendimento sobre ele, e ao se tornarem designers de um outro problema, eles podem ter se desmotivado por ser um contexto não muito confortável para eles.

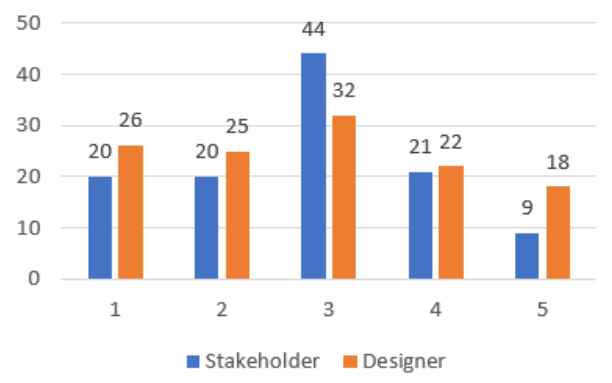

Figura 2: Nível de motivação dos alunos com a troca de papéis.

Por mais que não haja uma correlação entre desconforto e motivação e os resultados estejam equilibrados, os alunos entenderam o objetivo dessa dinâmica de troca de papéis. Um dos alunos, no relatório final do projeto escreveu:

"Essa dinâmica de troca de ideias foi muito boa, pois proporcionou uma criação de cenário, onde em um fomos designers e no outro clientes criando, assim, uma simulação de como é 
um projeto de desenvolvimento de design de uma aplicação no mercado de trabalho e proporcionando um entendimento de todos os contextos da área."

A troca de problemas e de papéis tinha por objetivo mostrar aos alunos que eles nem sempre irão atuar como designers em problemas que nem sempre terão pleno conhecimento do domínio da aplicação, mas que mesmo assim, precisam desenvolvê-lo do melhor modo possível. Um aluno, comentou que essa dinâmica traz realidade para a disciplina:

"A matérias de IHC proporcionou um cenário de aprendizagem muito bom, pois tivemos que desenvolver uma ideia de projeto realizada por terceiros, assim criando uma experiência mais próxima da realidade de como é ser um designer, porque é necessário desenvolver um protótipo a pedido de um cliente real, simulado por outro grupo, o que proporcionou uma experiência de interação como stakeholder de um projeto real."

A troca de papéis ainda demonstrou aos alunos a necessidade dos designers lidarem com stakeholders, destacando a importância da comunicação em um processo de design. Sobre isso, um aluno comentou o seguinte:

"Outro ponto de aprendizado importante foi a interação de ideias com outras pessoas, na qual opiniões deveriam ser discutidas entre o grupo, ao mesmo tempo que as ideias $e$ opiniões do grupo 'cliente' deveriam ser levadas em conta.”

A disciplina de IHC, muitas vezes, muda o paradigma de solução de problemas computacionais: se antes os alunos pensavam em algoritmos e na tecnologia, deixando a parte da interface apenas para a parte final do projeto, agora eles iniciam o processo de ideação de solução do problema focado no usuário e na sua experiência com a tecnologia. Assim, questionou-se aos alunos quão relevante eles serem stakeholders e designers alterou essa percepção sobre elaborar soluções de design que são focadas nos usuários e não na tecnologia.

A Figura 3 indica que os alunos acreditam que ser designer colaborou mais para que eles entendessem a importância de se focar nas necessidades dos usuários durante o processo de ideação de solução de um problema de design. Nesse contexto, um aluno destacou o seguinte:

"Aprendi a importância de entrevistar o usuário final desde o início do projeto, para levar em consideração as necessidades e expectativas do cliente. O contato com o usuário como parte do processo de design possibilita um desenvolvimento inteiramente focado nas partes essenciais para o sucesso do projeto e isto ficou muito claro durante este trabalho."

Alguns alunos destacaram a importância do usuário para se evitar problemas de interface, conforme o seguinte:

"Percebi que a parte do entendimento do problema e o envolvimento dos usuários durante todo processo é super importante, pois minimizam os erros criados, e a buscas por erros que não

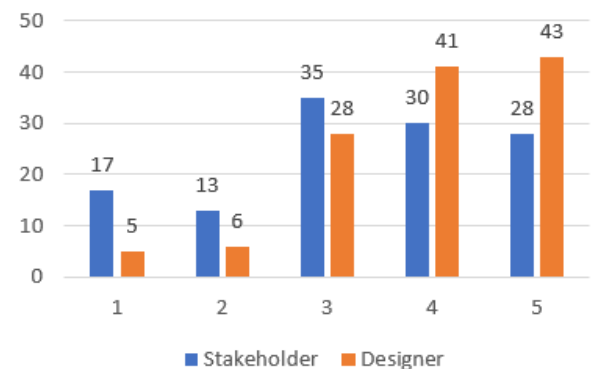

Figura 3: Nível de relevância dos papéis para elaborar soluções voltadas no usuário e não tecnologia.

perceberíamos, por conta de ser óbvio para nós designers, se tornaram mais eficientes."

"Agora tenho mais ferramentas para me auxiliar na criação e desenvolvimento de uma interface, tentando ao máximo prever quem serão os usuários do projeto, agregar ideias para diferentes diagramações/planejamentos, esboçar e testar protótipos antes de partir para um definitivo, e avaliar criticamente se o resultado obtido é realmente satisfatório, algo que antes era mais imediato e pulava muitas etapas, gerando muitos problemas posteriormente."

Um aluno ainda destacou que é preciso não considerar apenas guidelines no processo de design de uma interface:

"O projeto mostrou que para projetar uma interface, devemos sempre analisar as experiências do usuário, ressaltando que não devemos seguir somente as guidelines de especialistas."

O objetivo do desenvolvimento de uma solução de design para um problema, desde a fase de entendimento do problema e ideação inicial de solução, é aplicar a teoria vista durante as aulas em um "problema real" mostrando aos alunos como teorias se aplicam na prática e como elas podem facilitar o processo de design. Nesse contexto, os alunos foram indagados sobre quanto o projeto desenvolvido por eles contribuiu para o aprendizado dos conteúdos da disciplina. 51 alunos $(41,46 \%)$ responderam que o projeto contribuiu muito; 49 alunos $(39,83 \%)$ deram nota 4 na escala Likert, significando que o projeto contribuiu para o aprendizado da teoria; apenas 2 alunos responderam que não houve contribuição do projeto para o seu aprendizado. Alguns alunos relataram no relatório final que o projeto permitiu colocar em prática as teorias vistas em aula, possibilitando o entendimento delas bem como aprender novos conceitos:

"Durante todo o desenvolvimento do projeto pude não só aplicar conhecimentos antes adquiridos, mas também aprender novos conceitos, já colocando-os em prática, o que superou minhas expectativas iniciais."

"O desenvolvimento do projeto permitiu a aplicação de diversos conceitos vistos em sala de aula, e possibilitou não somente o entendimento teórico destes como também o que 
está envolvido nas suas implementações em situações práticas."

A fim de verificar qual papel (designer ou stakeholder) contribuiu mais para o aprendizado de conteúdos na disciplina de IHC, os alunos foram questionados sobre o quão relevante eles atuarem como stakeholder e como designers apoiou nesse objetivo. A Figura 4 revela que os alunos atuarem como designer colabora mais para o aprendizado de IHC do que ser stakeholder, enquanto que atuar como stakeholder mostrou-se ser menos relavante para os alunos; 33 alunos disseram que colabora pouco ou muito pouco para o aprendizado, aproximadamente 5 vezes mais do que os alunos que acreditam que ser designer não contribui. Um dos alunos escreveu no relatório final o seguinte:

"O desenvolvimento do projeto foi de extrema importância no aprendizado da disciplina. Com ele, pudemos saber na prática todas as dificuldades apresentadas durante as aulas expositivas, como "Como saber entender a demanda do usuário da melhor forma possível?”, "Como avaliar o design adequadamente?", "Como expressar da melhor forma as ideias que eu quero como stakeholder?”, etc. Ou seja, tanto as dificuldades como designer quanto como stakeholders foram trazidas como vivência."

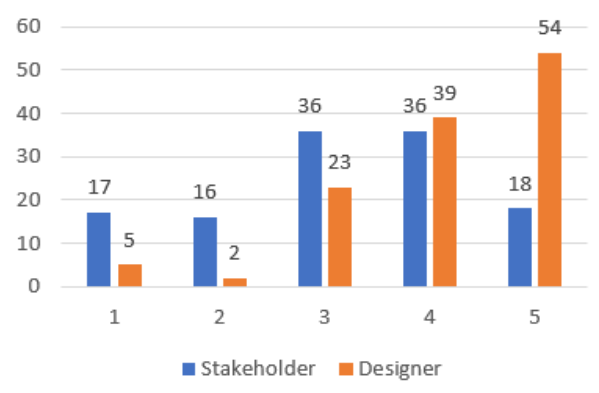

Figura 4: Colaboração dos papéis para o aprendizado de conceitos em IHC.

Em relação a ser stakeholder, um aluno destacou:

"Ser cliente foi enriquecedor em relação a aspectos como, aprender que não somente é difícil captar a ideia, mas também transmiti-la, isso de certa forma mudou minha mentalidade, me tornando mais simpática para com as dificuldades de um cliente."

O desenvolvimento de uma solução de design completa pelos alunos também visa ensiná-los sobre os desafios e dificuldades de aplicação das técnicas estudados na disciplina. Ao mesmo tempo que elas são facilitadoras para se obter soluções que podem ser mais efetivas para os usuários. Assim, foi questionado aos alunos se o desenvolvimento do projeto propiciou isso a eles. 78,86\% dos alunos indicaram que "sim", enquanto que 19,51\% disseram que "em parte". Alguns alunos comentaram que a disciplina permitiu refletir sobre todo o processo de design e sobre os diversos tipos de usuários existentes, reconhecendo a relevância de Acessibilidade, por exemplo:

"Aplicar o modelo de Ciclo de Vida (Entender, Estudar, Design, Construir e Avaliar) e trabalhar na construção do projeto com suas fases foram fundamentais para a fixação do aprendizado em IHC, além de agregar características reais para a disciplina, como verificar o problema em questão, tratar da sua viabilidade e comunicar-se com o cliente, resolver questões de projeto e saber avaliar o produto principalmente tentando prever problemas futuros."

"O curso também abriu meus olhos para a questão de inclusão e diversidade de usuários e da importância de criar um sistema com o qual todos consigam interagir (ou o mais próximo disso possível)."

O desenvolvimento de soluções de design possui diversos desafios e demandam diversas preocupações por parte dos designers. Dessa forma, ao atuarem como designers de um projeto com a presença de stakeholders "reais" deve tornar o processo de aprendizagem mais realístico. Por isso, foi perguntado aos alunos se o desenvolvimento do projeto permitiu que eles tivessem uma ideia dos desafios, dificuldades e cuidados que um designer deve ter no desenvolvimento de uma solução de design. Quase $85 \%$ dos alunos disseram que "sim", $13 \%$ disseram que "em parte" e 2,43\% disseram que "não". Dois alunos destacaram a aplicabilidade da disciplina para, sobretudo, trazer situações reais para a disciplina:

"A disciplina de IHC, muito por meio das atividades práticas, mostrou-se muito proveitosa, individualmente falando, uma vez que simula situações que frequentemente se repetem no contexto de desenvolvimento conjunto de software e das quais nunca presenciei e nem tive uma amostra de como eram, provendo portanto a um aluno leigo como eu uma boa ideia do que encontrarei nessas situações."

"Agora enxergo produtos e serviços de uma forma muito mais complexa, e tenho mais base para avaliar e tomar decisões de projeto. Isso é fruto da grande aplicabilidade da matéria."

Ao estabelecer uma dinâmica na qual os alunos foram demandados a atuarem ora como stakeholder e ora como designer fez com que os alunos enfrentassem algumas dificuldades no processo de design.

Ao serem stakeholders, os alunos destacaram o seguinte:

"Transmitir minhas expectativas aos designers"

"Saber que tipo de informação o outro grupo procurava respostas"

"Não ter certeza se o designer entendeu exatamente a ideia que eu queria passar sobre o que eu esperava do software"

"Ter uma ideia de solução e receber uma diferente dos designers do outro grupo"

"Acompanhar o andamento do outro projeto"

Já como designers, os alunos destacaram as seguintes dificuldades: 
"Pensar em todas as reais necessidades do usuário"

"Não entender direito o que o cliente queria"

"Entender o problema do stakeholders foi a parte mais difícil do projeto"

"Pensar em soluções de design que estivessem de acordo com o esperado inicialmente pelos stakeholders"

"Minha maior dificuldade foi obter uma avaliação dos stakeholders, para saber se a solução foi satisfatória"

"Pensar em soluções que são novas e eficientes"

"pensar sob o ponto de vista dos usuários, passar a ideia pensada de uma maneira clara e objetiva"

"Internalizar a ideia de focar no usuário e não no produto".

Consideramos que é notório que o desenvolvimento de um projeto prático para propor a solução de design para um problema apoia o aprendizado da teoria que fundamenta a área de IHC, bem como é um meio para que os alunos possam aplicar e entender de modo mais eficaz técnicas que propiciam e facilitam o desenvolvimento de soluções que são focadas nos usuários. Adicionalmente, isso permite que os alunos aprendam novos conceitos, presenciem situações que há no mundo real e entendam a importância de considerar o usuário durante todo o processo de design e não foquem apenas em algoritmos e/ou guidelines de desenvolvimento de interface.

A troca de papéis e de problemas tornou esse processo de aprendizado ainda mais realístico por demandar que eles sintam a dificuldade de um usuário em explicar o problema para um designer e de um designer em entender o que o usuário deseja. Ainda, a dinâmica pedagógica proposta propiciou o aprimoramento da experiência dos alunos por terem que aprender a lidar com problemas e situações que fogem do seu escopo de conhecimento.

\section{CONCLUSÃO}

O processo de ensino aprendizagem da disciplina de IHC no ensino superior demanda novas abordagens que considerem uma vivência prática dos alunos em atividades de design e avaliação de interfaces de usuários. Neste artigo, apresentamos uma estratégia pedagógica baseada em troca de papéis para o ensino de IHC. Nela grupo de alunos atuaram simultaneamente como designers e stakeholders com interações intra e extra grupo para aprimorar o entendimento e aprendizagem de atividades de design como clarificação do problema design, aplicação de técnicas de design participativo para a construção de protótipos de baixa fidelidade, construção e avaliação de protótipos de alta fidelidade.

A estratégia pedagógica proposta foi aplicada no decorrer de dois períodos letivos (2/2018 e 1/2019) para alunos da disciplina "Construção de Interfaces Homem-Computador" ministrada no Instituto de Computação da UNICAMP. Após aplicada, em cada semestre, foi solicitado que os alunos do curso respondessem um questionário com suas impressões em relação a dinâmica do projeto desenvolvida na disciplina, contendo perguntas específicas à estratégia proposta.

Os estudantes vivenciaram o papel de designers durante o desenvolvimento de um projeto baseado em um tema que não dominavam. Os alunos aturam no papel de cliente de um projeto e aprenderam as dificuldades de se transmitir suas ideias para contribuir na ideação das interfaces. Descobrimos que apesar de um certo grau de desconforto dos alunos com relação a troca de temas dos projetos, $96 \%$ dos discentes afirmaram que o desenvolvimento do projeto auxiliou no aprendizado de conteúdos da disciplina de IHC. Os alunos descreveram a importância de trabalharem com e como stakeholders, relatando principalmente a dificuldade de comunicação, que pode ser vivenciada durante o andamento do projeto.

Trabalhos futuros envolvem um refinamento da estratégia pedagógica e avaliações mais aprofundadas das percepções dos alunos.

\section{AGRADECIMENTOS}

Agradecemos aos aluno(a)s por desenvolveram os projetos e por responderem ao questionário proposto; ao Programa de Estágio Docente (PED) da PRPG da Universidade Estadual de Campinas (UNICAMP) pelo apoio financeiro aos monitores que auxiliaram no desenvolvimento da disciplina juntamente com o docente responsável; e ao Laboratório de Interação Humano-Artefato Digital (LInterHAD) do IC/UNICAMP.

\section{REFERÊNCIAS}

[1] Yuska Paola Costa Aguiar and Daniel Scherer. 2016. Da teoria à prática: uma abordagem de ensino de IHC baseado em papéis. In Anais do VII Workshop sobre educação em IHC no XV Simpósio Brasileiro sobre Fatores Humanos em Sistemas Computacionais (WEIHC 2016). ACM, 25-30.

[2] Willian N Bender. 2015. Aprendizagem baseada em projetos: educação diferenciada para o século XXI. Penso Editora.

[3] Luis Roberto de Camargo Ribeiroa. 2008. Aprendizagem baseada em problemas (PBL) na educação em engenharia. Revista de Ensino de Engenharia 27, 2 (2008), 23-32.

[4] Robert Delisle and Vitor Oliveira. 2000. Como realizar a aprendizagem baseada em problemas. Edições Asa.

[5] Jan Gulliksen, Bengt Göransson, Inger Boivie, Stefan Blomkvist, Jenny Persson, and Åsa Cajander. 2003. Key principles for user-centred systems design. Behaviour \& Information Technology 22, 6 (2003), 397-409.

[6] Douglas Schuler and Aki Namioka. 1993. Participatory design: Principles and practices. CRC Press. 